\title{
Análise estrutural das representações sociais da terapia antirretroviral entre pessoas que vivem com HIV/Aids: possibilidades de convivência, normatividade e ressignificação
}

\section{Structural analysis of social representations of antiretroviral therapy among people living with HIV/AIDS: possibilities of coexistence, normativity and ressignification}

\author{
Tadeu Lessa da Costa ${ }^{1}$ \\ Denize Cristina de Oliveira ${ }^{2}$ \\ Gláucia Alexandre Formozo ${ }^{3}$ \\ Antonio Marcos Tosoli Gomes ${ }^{4}$
}

\begin{abstract}
RESUMO: Objetivos: identificar e analisar os conteúdos e a estrutura das representações sociais da terapia antirretroviral entre pessoas que vivem com o vírus da imunodeficiência humana. Método: estudo descritivo e qualitativo. Os sujeitos foram 84 pessoas soropositivas acompanhadas em centro especializado de município norte-fluminense, Brasil. Empregou-se a técnica de evocação livre de palavras ao termo indutor terapia antirretroviral, com análise pelo quadro de quatro casas e software EVOC. Resultados: identificou-se como prováveis elementos do núcleo central da representação ter vida, tem que tomar e horário certo. Observou-se subgrupo com representação mais positiva permeada pelos conteúdos de compromisso, esperança e perspectiva de viver melhor. A periferia revelou facetas positivas e negativas quanto aos conteúdos, refletindo a complexidade da representação em questão. Conclusão: a representação em estudo mostrou-se predominantemente funcional, constituindo-se como subsídio para intervenções profissionais em saúde e enfermagem na promoção da adesão terapêutica e qualidade de vida de pessoas soropositivas.
\end{abstract}

Palavras-chave: síndrome da imunodeficiência adquirida; terapia antirretroviral de alta atividade; adesão à medicação; psicologia social; enfermagem.

\begin{abstract}
Objectives: to identify and analyze the content and structure of social representations of antiretroviral therapy among people living with the human immunodeficiency virus. Method: descriptive and qualitative study. The subjects were 84 HIV positive people in follow-up in specialized center municipality North Fluminense, Brazil. We applied the technique of free recall of words to the inductive term antiretroviral therapy, with analysis using four-frame houses and software EVOC. Results: identified as probable core elements of representation to have life, tp have take and exact time. Observed subgroup with more positive representation permeated the contents of commitment, hope and prospect of a better life. The periphery showed positive and negative facets as to content, reflecting the complexity of the representation in question. Conclusion: The study showed representation is predominantly functional, constituting as a basis for interventions in health and nursing professionals in promoting adherence and quality of life of people living with HIV.
\end{abstract}

Keywords: acquired immunodeficiency syndrome; highly active antiretroviral therapy; medication adherence; social psychology; nursing.

\section{Introdução}

Desde o surgimento de seus primeiros casos, no Brasil, no início da década de 1980, a epidemia do Vírus da Imunodeficiência Humana (HIV) e da Síndrome da Imunodeficiência Adquirida (AIDS), sofreram uma série de transformações em suas diversas dimensões. Passou-se de uma doença concentrada em metrópoles, predominantemente masculina, que atingia, em sua maioria, indivíduos com práticas sexuais homossexuais e hemofílicos, para um agravo com maior incidência sobre sujeitos com práticas sexuais heterossexuais, distribuição em quase todo o território nacional, progressiva redução da relação masculino/feminino, aumento entre pessoas com 50 anos ou mais e maior participação de grupos empobrecidos, com menor

\footnotetext{
${ }^{1}$ Doutor em Psicologia Social; Professor Adjunto do Curso de Enfermagem e Obstetrícia da Universidade Federal do Rio de Janeiro - Campus Macaé Professor Aloísio Teixeira (UFRJ - Campus Macaé) - Rio de Janeiro, Brasil. E-mail: tadeulessa@yahoo.com.br.

${ }^{2}$ Doutora em Saúde Pública; Professora Titular da Faculdade de Enfermagem da Universidade do Estado do Rio de Janeiro (UERJ). Professora dos Programas de Pós-Graduação em Enfermagem e em Psicologia Social da UERJ - Rio de Janeiro, Brasil.

${ }^{3}$ Doutora em Psicologia Social; Professora Assistente do Curso de Enfermagem e Obstetrícia da Universidade Federal do Rio de Janeiro - Campus Macaé Professor Aloísio Teixeira (UFRJ - Campus Macaé) - Rio de Janeiro, Brasil.

${ }^{4}$ Doutor em Enfermagem; Professor Titular da Faculdade de Enfermagem da Universidade do Estado do Rio de Janeiro (UERJ). Professor do Programa de Pós-Graduação em Enfermagem da UERJ - Rio de Janeiro, Brasil.
} 
escolaridade e qualificação profissional (Grangeiro, Escuder \& Castilho, 2010).

Uma dimensão com relevância adicional, na qual se observou mudança significativa consiste no tempo de sobrevida das pessoas que vivem com a doença. Este aspecto teve início a partir da década de 1990, sobretudo, com os avanços no desenvolvimento da terapia antirretroviral altamente ativa (HAART) contra o HIV (Hallal, Ravasi, Kuchenbecker, Greco \& Simão, 2010; Oliveira, 2013).

Estes medicamentos passaram a ter distribuição universal e gratuita no Brasil, a partir da lei 9.313/96 (Hallal et al., 2010). Assim, a taxa de mortalidade que era de 9,6 por 100.000 habitantes, em 1996, reduziu-se, progressivamente, para 6,4 por 100.000, em 1999 e, em 2009, foi de 6,2 por 100.000 (Reis, Santos \& Cruz, 2007; Brasil, 2010).

Estudo recente de coorte envolvendo 80.642 sujeitos com HIV em diferentes países europeus, que iniciaram uso de HAART após 1998, não usavam drogas ou com contagem de CD4 acima de $500 / \mathrm{mm}^{3}$ em, no mínimo, três anos seguidos, tiveram estimada a mesma probabilidade de sobrevivência que homens não infectados pelo vírus (Lewden et al., 2008). Desta maneira, as classes de antirretrovirais disponíveis e suas combinações viáveis levaram à transformação da aids em um agravo de natureza crônica (Oliveira, 2013).

Entretanto, uma importante faceta na abordagem ao uso da HAART consiste na adesão terapêutica por parte das pessoas que vivem com HIV/Aids (PV-HIV/Aids). E diversos estudos têm apontado para as dificuldades presentes neste processo, sendo descrito como elementos intervenientes na adesão aos referidos fármacos: efeitos colaterais; condições financeiras (Santos, Drumond, Gomes, Corrêa \& Freitas, 2011); quantitativo de medicamentos e complexidade terapêutica; impacto nas atividades de vida diária; suporte social (Torres \& Camargo, 2008; Santos et al., 2011); problemas emocionais; uso de drogas (Torres \& Camargo, 2008); e organização dos serviços de saúde e a interação com os profissionais de acompanhamento (Nemes et al., 2009).

Além disso, o universo simbólico associado ao HIV/Aids e à HAART apresenta, igualmente, repercussões para a convivência com o agravo e adesão ao uso correto das medicações (Cardoso \& Arruda, 2004; Torres \& Camargo, 2008; Gomes, Silva \& Oliveira, 2011). E, entre as abordagens psicossociais, a teoria de representações sociais consiste em instrumento relevante para a compreensão desta problemática, trazendo aporte teórico-metodológico para proposição de intervenções em saúde e enfermagem voltadas à promoção da adesão das PVHIV/Aids à terapêutica antirretroviral. Isto, pois ao se almejar as transformações nas práticas de saúde é necessário pensá-las em sua expressão objetiva e subjetiva, haja vista serem as mesmas operacionalizadas por pessoas, que agem segundo suas representações do real e do possível (Oliveira, 2013).

Compreende-se que as representações sociais são "uma forma de conhecimento socialmente elaborada e partilhada, com um objetivo prático, e que contribui para a construção de uma realidade comum a um conjunto social" (Jodelet, 2001, p.22). E, na perspectiva de autores da abordagem estrutural da teoria de representação social, as representações seriam constituídas por dois sistemas complementares: um central, que conferiria seu significado, a organização de seus conteúdos e maior estabilidade; e um periférico, o qual propiciaria a integração no núcleo comum com as experiências pessoas cotidianas e a proteção do sistema central, sendo, também, indicador de processos de mudança (Abric, 2003a, 2003b).

Assim, algumas investigações sobre as representações sociais da aids descrevem-na para as PV-HIV/Aids como algo que traz dificuldades, mas com a qual seria possível viver com auxílio das medicações. A presença deste conteúdo representacional tenderia a favorecer a adesão terapêutica, encontrando elementos de apoio, não apenas no campo do senso comum, mas, também, no saber científico (Cardoso \& Arruda, 2004; Torres \& Camargo, 2008; Gomes et al., 2011). Por outro lado, conteúdos representações sociais da aids caracterizando-a como algo ameaçador e enfrentada com estratégias de negação estariam mais associados ao perfil de não aderência à HAART. Neste caso, a medicação consistiria na própria objetivação indesejável da doença no cotidiano (Cardoso \& Arruda, 2004).

Haja vista serem escassos os estudos a respeito da relação entre as PV-HIV/Aids e a HAART na abordagem estrutural das representações sociais, este estudo tem por questões: quais os conteúdos representacionais acerca da terapia antirretroviral para as PV-HIV/Aids? Que 
elementos estariam presentes nos sistemas central e periférico desta representação? Com isso, tem-se por objetivos: identificar e analisar os conteúdos e a estrutura das representações sociais da terapia antirretroviral na perspectiva das PV-HIV/Aids.

\section{Método}

Trata-se de estudo descritivo, qualitativo, pautado na abordagem estrutural da teoria das representações sociais (Abric, 2003a, 2003b; Pecora \& Sá, 2008; Pianelli, Abric \& Saad, 2010; Oliveira, 2013). Foi aprovado em Comitê de Ética em Pesquisa da Universidade do Estado do Rio de Janeiro sob o no de protocolo 017.3.2011 e Certificado de Apresentação para Apreciação Ética 0009.0.325.000-11.

A amostragem da pesquisa foi do tipo não probabilística, por conveniência, sendo constituída por 84 sujeitos. Os critérios de inclusão foram os seguintes: ser PV-HIV/Aids; encontrar-se em uso de HAART; ter idade maior ou igual a 18 anos; estar em condições mentais que viabilizassem a participação no estudo; manifestar concordância em participar do mesmo; e localizar-se no cenário de estudo no momento da coleta de dados.

O cenário do estudo foi um Serviço de Assistência Especializada em HIV/Aids (SAE) localizado em um município de médio porte na região norte do estado do Rio de Janeiro. A coleta de dados ocorreu entre os meses de maio e outubro de 2011, abarcando todos os dias de atendimento na semana, de modo aleatório.

Para a coleta de dados foi empregado formulário com questões sóciodemográricas e de saúde, bem como a técnica de evocações livres ou associação livre de palavras. Esta técnica possui duas fases. Na primeira, cada sujeito deve indicar palavras ou expressões que venham imediatamente à sua mente a partir de um termo indutor. O caráter espontâneo deste processo permite ter acesso rapidamente ao universo semântico do objeto estudado (Abric, 2003b; Pianelli et al., 2010). Para a presente pesquisa, o termo indutor empregado foi "terapia antirretroviral", sendo orientada a produção de, ao máximo, cinco itens. Na segunda fase da técnica em questão, é demandado ao sujeito que proceda à classificação das evocações realizadas em função da importância que seja atribuída às mesmas para definir o objeto em questão (Abric, 2003b; Pianelli et al., 2010). O registro das evocações enunciadas pelos participantes se deu, também, em instrumento específico.

A análise dos dados sóciodemográficos e de saúde ocorreu por meio da estatística descritiva, com auxílio do software SPSS, versão 17. Para as evocações livres, o processo analítico inicial consistiu em padronizar as evocações dos sujeitos no corpus. Primeiramente, fez-se correção ortográfica, substituição das preposições e espaços por hífen, uniformização dos termos na forma plural ou singular e por gênero, conforme cada caso. Posteriormente, buscouse a homogeneização das evocações para a redução da dispersão de seus conteúdos, classificando sob a mesma designação elementos com significação comum.

Assim, foi possível obter um corpus de elementos e dois indicadores quantitativos para cada um destes: sua frequência de evocação e a ordem média de importância (OMI) atribuída pelos sujeitos (rang). O cruzamento, então, entre a frequência de evocação e o rang médio de importância de cada conteúdo representacional permite obter uma primeira identificação da organização da representação, considerando seus prováveis constituintes do sistema central e aqueles do sistema periférico (Pianelli et al., 2010). Os cálculos envolvidos no cruzamento entre os referidos indicadores para o corpus de análise se deu com auxílio do software Ensemble de programmes permettant l'analyse des evocations (EVOC), versão 2005.

O software EVOC, com base nos indicadores citados anteriormente, possibilitou a construção de um quadro com quatro quadrantes, que abarcam quatro zonas em uma representação social, interpretadas à luz da abordagem estrutural da referida teoria. Assim, há a zona do núcleo central, no quadrante superior esquerdo, com cognições mais frequentes e importantes. Estes itens podem ser centrais na representação, estereótipos ou protótipos associados ao objeto em foco (Abric, 2003b; Pianelli et al., 2010).

A zona de elementos de contraste, no quadrante inferior esquerdo, abrange termos enunciados por poucos sujeitos, mas avaliados como mais importantes para os mesmos. Além 
disso, alguns subgrupos poderiam apresentar representações distintas do grupo como um todo, cujas cognições centrais estariam nesta área (Abric, 2003b; Pianelli et al., 2010).

A zona da primeira periferia, no quadrante superior direito, contém itens mais evocados, mas considerados menos importantes pelos participantes (Abric, 2003b; Pianelli et al., 2010). São os componentes mais relevantes da periferia, podendo alguns de seus integrantes serem, eventualmente, centrais na representação, se confirmada por outro critério esta hipótese (Pecora \& Sá, 2008). Finalmente, a zona da segunda periferia corresponderia ao quadrante inferior direito, com cognições menos frequentes e menos importantes para a determinação do significado da representação (Abric, 2003b; Pianelli et al., 2010).

\section{Resultados}

Considerando o perfil sóciodemográfico dos participantes da pesquisa, observou-se distribuição aproximada quanto ao sexo, sendo $53,6 \%(n=45)$ homens e $46,4 \%(n=39)$ mulheres. A idade oscilou entre 20 e 67 anos, com média de 41,4 anos $( \pm 11,1)$, predominado, portanto, a faixa etária entre 30 e 49 anos, com $61,9 \%$ ( $n=52)$. A maioria referiu encontrar-se casada ou em união estável, sendo $48,8 \%(n=41)$, seguido pelos solteiros ou sem parceiro fixo, com $38,1 \%$ $(n=32)$.

Quanto ao nível de escolaridade, $54,8 \%$ ( $n=46)$ possuíam, ao menos, o ensino fundamental completo e $34,5 \%(n=29)$ o apresentavam incompleto. Para a variável trabalho, notou-se ser próxima a distribuição dos subgrupos, haja vista que $54,8 \%(n=46)$ não se encontravam inseridos no mercado de trabalho, estando os demais em atividade laboral. Por sua vez, no que diz respeito à renda pessoal mensal dos sujeitos destacaram-se aqueles com ganhos entre 1,1 e 3 salários mínimos (SM), com 32,1\% ( $n=27)$, seguidos por até 1 (SM), com $31 \%(n=26)$.

Em relação aos aspectos de saúde, a maioria referiu estar assintomática para o HIV/Aids $(72,6 \%, n=61)$, com nível de TCD4+ para 42,9\% ( $n=36)$ igual ou maior que $500 \mathrm{cel} / \mathrm{mm}^{3}$, seguido por $38,1 \% \quad(n=32)$, com este valor entre 499 e 200 , tendo, majoritariamente, carga viral indetectável $(66,6 \%, n=56)$. O tempo de diagnóstico da infecção pelo HIV foi, em média de 9,1 anos $( \pm 6,4)$, sendo o valor médio do uso de HAART de 7,3 anos $( \pm 5,8)$.

No que concerne às representações sociais da terapia antirretroviral, houve a produção pelos participantes de 413 palavras ou expressões, sendo 63 diferentes. A média das ordens médias de importância das evocações, ou seja, o rang médio calculado com auxílio do EVOC foi 2,9 , sendo mínima de 8 para aparição no quadro de quatro casas. A frequência média foi 15 , a qual, junto ao rang médio, possibilitou a distribuição dos elementos pelos quadrantes correspondentes à estruturação da representação (Figura 1).

\begin{tabular}{|c|l|c|c|c|c|c|}
\multicolumn{2}{|c|}{$<\mathbf{2 , 9}$} & \multicolumn{2}{|c|}{$\geq \mathbf{2 , 9}$} \\
\hline FreqMed. & Termo evocado & Freq & OMI & \multicolumn{1}{|c|}{ Termo evocado } & Freq & OMI \\
\hline \multirow{3}{*}{$\geq \mathbf{1 5}$} & Ter vida & 21 & 2,2 & Reações ao medicamento & 51 & 3,1 \\
& Tem que tomar & 21 & 2,6 & Adaptação & 15 & 3,5 \\
& Horário certo & 19 & 2,4 & & & \\
\hline \multirow{5}{*}{$<\mathbf{1 5}$} & Responsabilidade & 10 & 2,3 & Controla a doença & 13 & 3,1 \\
& Viver bem & 10 & 2,8 & Para o resto da vida & 13 & 3,3 \\
& Esperança & 10 & 2,8 & Bom & 12 & 3,3 \\
& Melhora & 8 & 2,4 & Ruim & 12 & 3,4 \\
& & & & Deseja não tomar & 10 & 2,9 \\
& & & & Esconder o diagnóstico & 9 & 3,6 \\
& & & & Tranquilidade & 8 & 3,1 \\
\hline
\end{tabular}

Figura 1 - Estruturação da representação social da terapia antirretroviral para PV-HIV/aids, município nortefluminense, 2011. 
Assim, no quadrante superior esquerdo, correspondendo à zona do provável núcleo central na representação social em questão, foram identificados os termos ter vida, tem que tomar e horário certo. O primeiro item de evocação citado englobou enunciações relativas à ideia de vida e prolongamento da mesma na convivência com o HIV/Aids, com o auxílio da HAART. Trata-se da cognição com possível centralidade na representação em questão com maior frequência e menor OMI.

A cognição provavelmente central tem que tomar envolveu a padronização de evocações com conteúdos relacionados à obrigatoriedade de ingesta da HAART, sem a qual se correria o risco de morte. Apresentou segunda maior frequência na zona do núcleo central, entretanto com terceiro menor OMI.

Por sua vez, o último componente da zona do núcleo central da representação em tela consistiu no horário certo, abarcando preocupação com o seguimento do esquema terapêutico segundo os intervalos temporais prescritos para a administração da HAART. Observou-se para tal termo menor frequência de aparição entre os possivelmente centrais, porém com segundo menor OMI.

Deste modo, o provável sistema central identificado por meio das evocações livres e quadro de quatro casas parece apontar, essencialmente, para uma representação social da terapia antirretroviral para as PV-HIV/Aids com geração de significado e organização interna em torno de uma construção prescritiva quanto à necessidade de uso dos fármacos para a manutenção e prolongamento da vida com o agravo. Isto também geraria uma demanda cotidiana para observação dos intervalos temporais regulares na ingestão da HAART.

No quadrante inferior esquerdo, correspondente à zona de contraste, foram identificadas as cognições responsabilidade, viver bem, esperança e melhora. Haja vista os termos homogeneizados para a padronização dos referidos conteúdos representacionais, pode-se dizer que apontam, respectivamente, para: a assunção de disciplina no cotidiano com a HAART; desejo ou crença em um futuro melhor; e a possibilidade de incremento do estado de saúde. Os sujeitos envolvidos nestas enunciações apresentam, portanto, de maneira mais positiva a terapia antirretroviral, do que o conjunto dos participantes da pesquisa, como observado no quadrante superior esquerdo. Isto, especialmente, ao serem considerados os três últimos componentes de contraste citados.

No quadrante superior direito, que concerne à zona da primeira periferia da representação, constatou-se as cognições reações ao medicamento e adaptação. Cabe destacar que o primeiro item citado teve maior saliência na expressão do universo representacional em questão pelos sujeitos, com 51 aparições, bem como com OMI de 3,1, próximo ao valor de 2,9 adotado como corte para elegibilidade prototípica à zona central na estrutura da representação. Sob esta denominação foram agrupadas evocações com conteúdos alusivos, de modo genérico, às ocorrências de efeitos colaterais da HAART, incluindo sensação de mal-estar e outros registros mais específicos à respeito, como prostração, náuseas, sonolência, diarreia, cefaleia, insônia, gastrites e ganho de peso.

Quanto ao componente adaptação, constatou-se frequência de evocação limítrofe com a frequência média de 15 , critério quantitativo para inclusão na primeira periferia, e OMI com valor mais elevado de 3,5. Abarcou as evocações com conteúdos relativos: ao processo de aceitação do estado de soropositividade ao HIV e desdobramentos como o uso da HAART; as dificuldades na assunção da prática regular de emprego destes fármacos; e a preocupação em ter que fazer disto um hábito permanente.

Em relação ao quadrante inferior direito, em que se situa a segunda periferia da representação em questão, foram identificadas as cognições controla a doença, bom $e$ tranquilidade. Tais designações comportam, respectivamente, padronizações que expressavam: a ação dos referidos fármacos na interrupção da deterioração orgânica causada pela doença e, mesmo, pelo vírus HIV, segundo as produções de alguns participantes; uma dimensão atitudinal favorável às medicações; e a incorporação da tecnologia em foco vista como "normal", "comum", "tranquila" no cotidiano.

Ainda no quadrante em questão, figuraram as cognições para o resto da vida, ruim, deseja não tomar e esconder o diagnóstico. Englobam, respectivamente, conteúdos de evocação denotando: a cronicidade do agravo, a ausência de cura e de perspectiva de suspensão médica 
das medicações; dimensão atitudinal desfavorável aos fármacos; desgosto pela ingestão dos medicamentos, a volição e a incerteza quanto a deixar de utilizá-los por conta própria e o pesar pelo agravo, com a consequente necessidade do emprego regular dos mesmos; e a preocupação quanto à revelação forçada do diagnóstico de infecção pelo HIV devido ao uso da HAART, com o ocultamento de seus frascos e outros componentes do tratamento, não se devendo comentar com outras pessoas a respeito.

\section{Discussões}

No que diz respeito à caracterização do provável sistema central da representação em estudo, pode-se dizer que este possui ativação essencialmente funcional. Este perfil de centralidade ocorre em situações com uma finalidade operatória, nas quais são privilegiados na representação e constituirão o núcleo central os elementos mais importantes para a realização de determinada tarefa (Abric, 2003a), neste caso, o uso da HAART no cotidiano. Este predomínio funcional na representação poderia ser explicado, também, pelo efeito da proximidade dos sujeitos com o objeto social investigado (Abric, 2003a).

Como referido anteriormente, não se identificou estudos prévios sobre as representações sociais da terapia antirretroviral entre PV-HIV/Aids, na perspectiva da abordagem estrutural. Entretanto, pesquisas prévias a respeito na abordagem processual (Torres \& Camargo, 2008; Gomes et al., 2011), bem como com base em outros referenciais teóricos (Souto, 2008; Santos et al., 2011), apontam para a importância da introdução da HAART para a construção da ideia de possibilidade de conviver com o HIV/Aids, haja vista o impacto clínico sobre o curso da infecção e a consequente ampliação no tempo médio de vida com a doença. Este aspecto pode explicar a presença deste conteúdo representacional no núcleo central em questão.

Além disso, a referida cognição pode constituir-se em elemento com potencial para a inserção de mudança nas representações sociais do HIV/Aids, no âmbito da qual se constata o deslocamento dos conteúdos relacionados à morte da centralidade da representação (Oliveira, 2013). Consiste, assim, em fator com potencial motivacional à adesão terapêutica (Santos et al., 2011).

A questão das repercussões da HAART no cotidiano das PV-HIV/Aids quanto às restrições e tensão advindas da observação permanente dos horários de ingestão dos medicamentos foi constatada, igualmente, em investigações anteriores (Souto, 2008; Torres \& Camargo, 2008; Gomes et al., 2011; Santos et al., 2011). Assim, o uso contínuo da medicação e a necessidade de utilizar os remédios durante toda a vida caracterizam a situação crônica da doença (Torres \& Camargo, 2008). E as mudanças no cotidiano devido à rotina de uso de emprego dos fármacos podem repercutir, também, no trabalho dos sujeitos, abarcando, adicionalmente, a frequência às consultas médicas e exames periódicos nos SAE (Santos et al., 2011).

Nesta perspectiva, investigação sobre a adesão à HAART identificou como principal causa de abandono ou falha no uso destes medicamentos a mudança na rotina diária e o fato de estarem os sujeitos fora de casa nos horários de administração (Ilias, Carandina \& Marin, 2011). Deste modo, o conjunto das facetas descritas em torno desta cognição poderia justificar a sua centralidade e, portanto, seu potencial gerador e organizador na representação, como elemento sensível na relação com os antirretrovirais.

Em relação ao último elemento central tem que tomar, pensa-se que esteja associado com a cognição central ter vida, já que consistiria em condição indispensável para a manutenção e prolongamento da vida após a infecção pelo HIV (Souto, 2008; Torres \& Camargo, 2008; Gomes et al., 2011; Santos et al., 2011). Além disso, destaca-se seu caráter normativo e, portanto, potencialmente prescritivo para o cuidado em saúde, consistindo em percepção da imprescindibilidade dos fármacos em questão ou, mesmo, o reflexo de práticas discursivas verticais programáticas ou de profissionais em saúde, de modo parafrástico, como evidenciado em outro estudo sobre temática análoga (Gomes \& Cabral, 2009). Assim, poderia se constituir em um condicionante discursivo, mas com práticas eventualmente contraditórias de não adesão, caso não haja vínculo terapêutico efetivo e processo dialógico na construção do mesmo (Margalho, Paixão \& Pereira, 2010).

Em relação à zona de contraste, conforme pressupostos da abordagem estrutural (Abric, 2003a, 2003b), pode-se dizer representa um subgrupo com uma representação mais positiva 
acerca da terapia antirretroviral, com conteúdos de caráter menos funcionais, porém com maior presença de aspectos associados à espiritualidade. Isto, pois esta última abarca, para além do conceito de religiosidade, a significação da vida e as questões existenciais dos sujeitos, estando associado a um modo mais esperançoso de convivência com o HIV/Aids, como evidenciado em trabalhos anteriores (Panzini, Rocha, Bandeira \& Fleck, 2008; Galvão et al., 2012). Esta dimensão consiste em importante ponto de valorização e abordagem pelos profissionais de saúde e, especialmente, enfermagem, na assistência a PV-HIV/Aids, a qual possibilita melhor enfrentamento dos diversos desafios na convivência com o agravo, bem como melhoria da qualidade de vida (Galvão et al., 2012).

Adicionalmente, como descrito em estudo sobre a evolução das representações sociais da aids (Oliveira, 2013), poder-se-ia observar a possibilidade de um movimento de constituição de uma representação mais positiva sobre a terapia antirretroviral para as PV-HIV/Aids. Tal fenômeno se daria se continuado o processo de construção e partilhamento social de elementos carregados de espiritualidade no lidar com a HAART e com o agravo em foco.

Quanto aos componentes representacionais periféricos, deve-se destacar, inicialmente, o potencial de que o elemento reações ao medicamento possa fazer parte do núcleo central da representação. Neste sentido, autores da abordagem estrutural apontam para a possibilidade de elementos na zona da primeira periferia serem centrais, dado o caráter quantitativo da técnica de evocações livres, podendo ser empregados outros critérios como conexidade ou afinidade com outros componentes centrais como indicadores da posição efetiva de tais cognições na estrutura representacional (Pecora \& Sá, 2008).

Neste caso, a presença do conteúdo em questão no sistema central poderia conduzir, de modo complementar, a um significado da representação da terapia antirretroviral em termos da necessidade de uso da HAART, nos horários devidos, não obstante os efeitos colaterais, tendo como meta ou motivação a possibilidade de prolongamento de viver mais. $E$, mais claramente para um subgrupo objetivado na zona de contraste, viver melhor e com atitude mais positiva quanto ao futuro.

Salienta-se que os efeitos colaterais consistem em fator relevante na dinâmica de uso e adesão à HAART, especialmente, no início do emprego destes fármacos (Gomes \& Cabral, 2009). Assim, como demonstrado em outras pesquisas, seria importante a ativação de outros aspectos, como atenção e apoio no setor saúde, suporte social e percepção de melhora da saúde, para favorecer o enfrentamento das adversidades e continuidade do tratamento (Torres \& Camargo, 2008; Santos et al., 2011).

Conforme os pressupostos da abordagem estrutural, a periferia das representações sociais consiste em componente fundamental para a análise nos processos de mudanças representacionais em curso, possibilitando caracterizar indicadores de alterações no plano do significado e organização da representação (Abric, 2003a, 2003b). Neste caso, destaca-se a relevância da cognição adaptação presente na primeira periferia para o processo de evolução da representação social em questão, haja vista que carreia conteúdo voltado ao processo de progressiva incorporação e ajustamentos biopsicossociais necessários às PV-HIV/Aids diante do uso da HAART.

Isto, pois, esta adaptação no cotidiano envolve, para além da inserção propriamente dita das medicações e seus efeitos colaterais mais frequentes, a convivência com: a estigmatização; problemas no acesso e na atenção à saúde ofertada pelos serviços de saúde; barreiras na manutenção de vínculos empregatícios; alterações na vivência da sexualidade; mudanças alterações corporais e na percepção da autoimagem; e, não raro, dificuldades com o suporte social familiar e/ou ampliado (Cardoso \& Arruda, 2004; Souto, 2008; Panzini et al., 2008; Torres \& Camargo, 2008; Nemes et al., 2009; Hallal et al., 2010; Margalho et al., 2010; Ilias et al., 2011; Gomes et al., 2011; Santos et al., 2011; Galvão et al., 2012; Oliveira, 2013). Desta maneira, o posicionamento deste elemento na estrutura representacional pode operar como indicador da disposição interna, bem como da ativação de seu significado na relação do grupo com a terapia antirretroviral no contexto da vida com HIV/Aids.

No que concerne à segunda periferia na representação, tem-se a disposição de elementos com menor potencial para a determinação do significado e organização da representação. Entretanto, abarca aspectos relativos à realidade de inserção dos sujeitos, suas vivências e as 
modulações mais individualizadas na construção informativa, imagética e atitudinal diante do objeto social focalizado (Abric, 2003a, 2003b). Assim, a formação de nucleamentos de conteúdos positivos e negativos expressam a multiplicidade de experiências e a complexidade na convivência das PV-HIV/Aids com o agravo e com a HAART, bem como na elaboração das respectivas representações sociais, como reportado em pesquisas na área (Cardoso \& Arruda, 2004; Torres \& Camargo, 2008; Gomes et al., 2011).

Nesta perspectiva, as cognições mais positivas dispostas nesta situação na estrutura da representação parecem estar associadas e reforçar: a dimensão do léxico ter vida, no provável sistema central da representação; a lógica da adaptação na primeira periferia; e os aspectos presentes na zona de contraste. Deve-se salientar a identificação da ação da HAART em termos mais específicos apenas nesta localização da representação pela padronização controla $a$ doença, o que vai de encontro ao descrito em outro estudo em que foi saliente a apropriação do universo consensual na elaboração da representação social da aids para PV-HIV/Aids (Torres \& Camargo, 2008).

Ressalta-se, também, o papel da dimensão atributiva bom nesta posição na representação como um reforço prototípico e qualitativo adicional à significação presente no sistema central. Pensa-se que isto ocorre pela configuração da imprescindibilidade do uso da terapia antirretroviral para a sobrevivência com a doença (Souto, 2008; Torres \& Camargo, 2008; Gomes \& Cabral, 2009; Gomes et al., 2011; Santos et al., 2011). Por conseguinte, o caráter funcional referente a ter que tomar os medicamentos tenderia a sobrepor-se ao valorativo, não obstante ser este último de importante abordagem pelo profissional na busca de uma efetiva adesão medicamentosa (Navarro et al., 2011), pois diz respeito à atitude das PV-HIV/Aids quanto ao arsenal terapêutico.

Por sua vez, a cognição tranquilidade na segunda periferia, parece, igualmente, reforçar o sentido do léxico adaptação na primeira periferia e os aspectos dispostos na zona de contraste. Expressa, também, um modo menos extraordinário em lidar com os significados presentes na zona do sistema central, como ter que tomar e, sobretudo, no horário certo.

Entretanto, na tranquilidade mencionada deve-se registrar a eventual ocorrência de fenômeno referido em estudo anterior como "ilusão positiva", em que os sujeitos poderiam negar de maneira consciente a si mesmos situações ou condições com potencial para influenciar negativamente no desejo de uso adequado dos medicamentos e de superação de certas dificuldades associadas (Santos et al., 2011). E, assim, ainda que em outra perspectiva, reforçaria também o significado ensejado na cognição provavelmente central ter vida.

$\mathrm{Na}$ composição de nucleamento de caráter mais negativo na segunda periferia da representação, o elemento mais saliente para o resto da vida corrobora, também, o sentido da adaptação da primeira periferia e o possível sistema central. Isto, pois, nesta apropriação da HAART, ter que tomar, nos horários certos, para ter vida seria, igualmente, condição permanente. Na perspectiva da abordagem estrutural, inclusive, ressalta-se que a percepção de determinada mudança como perene, geralmente, está associada com transformação representacional mais rápida quanto a um dado objeto social (Flament, 2001).

Assim, embora o uso contínuo da terapia antirretroviral possa emergir como um fator de avaliação negativa da mesma, como demonstrado em outras pesquisas (Cunha, 2010; Gomes et al., 2011; Santos et al., 2011), em termos representacionais, tal característica pode promover subsídios simbólicos para a ativação de mecanismos de enfrentamento e adaptação à condição de soropositividade ao HIV e seus desdobramentos, como a necessidade de adesão terapêutica. Neste sentido, a doença, muitas vezes, se materializa no corpo com o uso das medicações no cotidiano, estabelecendo-se uma dialética entre esta prática e uma tentativa de não ceder ao lugar de doente, associado à depressão (Cunha, 2010).

O léxico ruim presente na segunda periferia, por seu turno, consiste em dimensão atributiva nas representações sociais (Abric, 2003a), abarcando uma disposição global negativa quanto à terapia antirretroviral. Parece estar em sinergia, sobretudo, com o elemento reações ao medicamento, na primeira periferia, bem como com os léxicos de horário certo, na zona do núcleo central, e para o resto da vida, também, na segunda periferia.

A este conjunto simbólico estaria expresso, consequentemente, o desejo de não tomar os fármacos, não obstante sua necessidade para a vida com o agravo em questão. Deste modo, 
algumas investigações apontam para a crença e a esperança de PV-HIV/Aids na possibilidade de advento de uma terapia que possa curá-las da infecção, motivo pelo qual usariam os medicamentos, já que estes possibilitariam manter a vida até tal descoberta. Esta, então, traria a concretude considerada legítima da liberação da rotina terapêutica (Cardoso \& Arruda, 2004; Torres \& Camargo, 2008).

Cabe salientar que a presença de conteúdos avaliativos opostos em bom e ruim nesta posição da estrutura representacional consiste em consequência da complexidade da relação com o HIV/Aids e com a HAART, como discutido anteriormente (Cardoso \& Arruda, 2004; Torres \& Camargo, 2008; Gomes et al., 2011; Oliveira, 2013). Reflete, igualmente, função de flexibilidade e participação de experiências mais individualizadas na constituição da representação social (Flament, 2001; Abric, 2003a, 2003b).

Em relação ao léxico esconder o diagnóstico, pensa-se que integra faceta negativa na segunda periferia da representação, remetendo à realidade social de inserção dos sujeitos como consequência da estigmatização em torno do HIV/Aids. Tal atitude discriminatória diante do agravo e das PV-HIV/Aids leva, frequentemente, as pessoas ao ocultamento de sua sorologia no ambiente de trabalho, entre amigos e, mesmo, no âmbito familiar, como modo de evitar prejuízos materiais e, sobretudo, sofrimento psíquico e social. Um dos elementos fundamentais para este processo consiste na imagem da doença ainda relacionada a condutas julgadas como socialmente desviantes (Gomes et al., 2011).

Como descreve investigação na área, o preconceito diante das PV-HIV/Aids, em função de passarem a sentir-se diferentes, associa-se a sentimentos negativos e a experiência de perda de um lugar social conhecido e que se acreditava ocupar, antes do diagnóstico (Cunha, 2010). Este processo de ocultamento do agravo e das medicações no cotidiano, inclusive, no âmbito domiciliar tende a desfavorecer a evolução de adaptação à vida com o agravo, bem como a adesão efetiva aos cuidados medicamentosos e outros eventualmente necessários, já que não se consegue o estabelecimento de dialogicidade a respeito de maneira efetiva. Traz, portanto, implicações para a prática profissional na atenção à saúde deste grupo na promoção de uma relação mais positiva com a doença e com as tecnologias envolvidas nesta convivência (Gomes \& Cabral, 2009).

\section{Conclusões}

O estudo possibilitou o desvelamento dos conteúdos e da disposição destes na estrutura da representação social referente à terapia antirretroviral entre PV-HIV/Aids. Identificou-se elementos como prováveis componentes do sistema central da representação e de seu sistema periférico, haja vista suas funções, respectivamente, geradora, organizadora e estabilizadora, bem como de flexibilidade e incorporação das práticas e experiências mais individualizadas no processo de convivência com o agravo e com o uso da HAART.

Assim, caracterizou-se um provável sistema central composto pelas cognições ter vida, tem que tomar e horário certo, remetendo a uma perspectiva de apropriação mais funcional da relação das PV-HIV/Aids com a terapia antirretroviral no cotidiano. Haveria, então, a necessidade de utilização dos fármacos em questão para a manutenção da vida, exigindo a observação de intervalos temporais específicos no processo. Foi, igualmente, apontada a possibilidade de centralidade na representação estudada das reações ao medicamento, dada sua saliência na periferia da representação e possível associação a componentes da zona do núcleo central.

O estudo revelou, também, a existência de um subgrupo de sujeitos com uma representação social mais positiva quanto ao objeto social analisado. Isto, pois, se observou um conjunto de evocações relativo ao compromisso e disciplina com a terapêutica e a uma maior espiritualidade e esperança no enfrentamento diante da doença e do uso das medicações.

Os demais componentes representacionais no sistema periférico mostraram-se em dois subconjuntos, definidos em torno de sua disposição global quanto à terapia antirretroviral. Assim, constatou-se a presença de cognições de caráter mais positivo e outras de natureza mais negativa quanto ao referido objeto, refletindo a complexidade na representação social focalizada e nas práticas sociais relacionadas. 
Os achados do estudo remetem, portanto, ao necessário trabalho dos profissionais de saúde, especialmente, os de enfermagem na compreensão dos elementos que definem o uso da terapia antirretroviral para as PV-HIV/Aids, considerando o reforço a aspectos positivamente relacionados com a adesão e qualidade de vida. Deve-se, igualmente, promover abordagens dialógicas grupais e individuais para contribuir com a desconstrução de facetas representacionais negativas quanto aos desfechos citados, haja vista a função das representações como guia para a ação.

Pensa-se que se constitui em aspecto para aprofundamentos em pesquisas posteriores o movimento na estruturação interna nas representações sociais da terapia antirretroviral, especialmente, dos elementos adaptação e aqueles identificados na zona de contraste. Pensase que, com isso, haveria a possibilidade de acompanhamento de indicadores simbólicos potenciais de uma apropriação mais positiva diante da doença e, mais especificamente, da HAART.

Como desdobramento quanto a relações representacionais externas, pensa-se ser pertinente perscrutar, posteriormente, a relação estabelecida no plano estrutural entre as representações sociais da terapia antirretroviral e da aids. Este fato se dá pela relação entre os dois objetos em questão já apontada em termos de conteúdos representacionais, com repercussões para propor intervenções profissionais que considerem o impacto sinérgico diante da convivência com o agravo e com a HAART.

\section{Referências}

Abric J-C. (2003a). A abordagem estrutural das representações sociais: desenvolvimentos recentes. Em P. H. F. Campos \& M. C. S. Loureiro. Representações sociais e práticas educativas (pp. 37-57). Goiânia (GO): Ed. UCG.

Abric, J-C. (2003b). La recherche du noyau central et la zone muette des représentations sociales. Em J-C. Abric (Org.). Méthodes d'études des représentations sociales (pp. 60-80). Ramonville Saint-Agne.

Brasil. Ministério da Saúde. (2010). Boletim epidemiológico AIDS 1 27a/2009 a 52a/2009 1å/2010 a 26a 2010. Brasília: Ministério da Saúde.

Cardoso, G. P., \& Arruda, A. (2004). As representações sociais da soropositividade e sua relação com a observância terapêutica. Ciência \& Saúde Coletiva, 10(1), 151-162.

Cunha, C. C. (2010). Entre tramas e dramas: os significados do tratamento para mulheres de camadas populares vivendo com HIV/Aids. Physis, 20(3), 931-951. Recuperado de http://www.scielo.br/pdf/physis/v20n3/v20n3a13.pdf.

Flament, C. (2001). Estrutura e dinâmica das representações sociais. Em D. Jodelet (Org.). As representações sociais (pp. 173-86). Rio de Janeiro: EdUERJ.

Galvão, M. T. G., Bonfim, D. Y. G., Gir, E., Carvalho, C. M. L., Almeida, P. C., \& Balsanelli, A. C. S. (2012). Esperança em mulheres portadoras da infecção pelo HIV. Revista da Escola de Enfermagem da USP, 46(1), 38-44.

Gomes, A. M. T., \& Cabral, I. E. (2009). O cuidado medicamentoso à criança com HIV: desafios e dilemas de familiares cuidadores. Revista Brasileira de Enfermagem, 62(2), 252-257.

Gomes, A. M. T., Silva, E. M. P., \& Oliveira, D. C. (2011). Social representations of AIDS and their quotidian interfaces for people living with HIV. Revista Latino-Americana de Enfermagem, 19(3), 485-492.

Grangeiro, A., Escuder, M. M. L., \& Castilho, E. A. (2010). Magnitude e tendência da epidemia de aids em municípios brasileiros de 2002-2006. Revista de Saúde Pública, 44(3), 430-441.

Hallal, R., Ravasi, G., Kuchenbecker, R., Greco, D., \& Simão, M. (2010). O acesso universal ao tratamento antirretroviral no Brasil. Revista Tempus Actas de Saúde Coletiva, 4(2), 53-66.

Ilias, M., Carandina, L., \& Marin, M. J. S. (2011). Adesão à terapia antirretroviral de portadores do vírus da imunodeficiência humana atendidos em um ambulatório em Marília, São Paulo. Revista Baiana de Saúde Pública, 35(2), 471-484.

Jodelet, D. (2001). Representações Sociais: um domínio em expansão. Em D. Jodelet (Org.). As representações sociais (pp. 17-44). Rio de Janeiro: EdUERJ.

Lewden, C., May, T., Rosenthal, E., Burty, C., Bonnet, F., Costagliola, D., Jougla, E., Semaille, C., Morlat, P., Salmon, D., Cacoub, P., Chêne, G., \& ANRS EN19 Mortalité Study Group and Mortavic1. (2008). Changes in causes of death among adults infected by HIV between 2000 and 2005: The "mortalité 2000 and 2005" surveys (ANRS EN19 and Mortavic). Journal of Acquired Immune Deficiency Syndromes, 48(5), 590-598.

Margalho, R., Paixão, R., \& Pereira, M. (2010). Relação terapêutica e adesão em doentes portadores da infecção pelo Vírus da Imunodeficiência Humana (VIH). Psicologia, Saúde \& Doenças, 11(1), 71-81. 
Navarro, A. M. A., Bezerra, V. P., Oliveira, D. A., Moreira, M. A. S. P., Alves, M. S. C. F., \& Gurgel, S. N. (2011). Social representations of the HIV/Aids: perception of the primary health care professionals. Revista de Pesquisa: Cuidado é Fundamental, ed. supl, 92-99. Recuperado de http://seer.unirio.br/index.php/cuidadofundamental/article/view/1966/pdf_529.

Nemes, M. I. B., Castanheira, E. R. L., Helena, E. T. S., Melchior, R., Caraciolo, J. M., Basso, C. R., Britto e Alves, M. T. S. S., Alencar, T. M. D., \& Ferraz, D. A. S. (2009). Adesão ao tratamento, acesso e qualidade da assistência em aids no Brasil. Revista da Associação Médica Brasileira, 55(2), 207-212.

Oliveira, D. C. (2013). Construction and transformation of social representations of Aids and implications for health care. Revista Latino-Americana de Enfermagem, 21(spec), 276-286.

Panzini, R. G., Rocha, N. S., Bandeira, D. R., \& Fleck, M. P. A. (2008). Espiritualidade/religiosidade e qualidade de vida. Em M. P. A. Fleck (Org.). A avaliação de qualidade de vida: guia para profissionais de saúde (pp. 17796). Porto Alegre: Artmed.

Pecora, A. R., \& Sá, C. P. (2008). Memórias e representações sociais da cidade de Cuiabá, ao longo de três gerações. Psicologia: Reflexão e Crítica, 21(2), 319-325.

Pianelli, C., Abric, J-C., \& Saad, F. (2010). Rôle des representations sociales préexistantes dans les processus d'ancrage et structuration d'une nouvelle representation. Cahiers Internationaux de Psychologie Sociale, 86, 241-274.

Reis, A. C., Santos, E. M., \& Cruz, M. M. (2007). A mortalidade por aids no Brasil: um estudo exploratório de sua evolução temporal. Epidemiologia e Serviços de Saúde, 16(3), 195-205.

Santos, W. J., Drumond, E. F., Gomes, A. S., Corrêa, C. M., \& Freitas, M. I. F. (2011). Barreiras e aspectos facilitadores da adesão à terapia antirretroviral em Belo Horizonte-MG. Revista Brasileira de Enfermagem, 64(6), 1028-1037.

Souto, B. G. A. (2008). O HIV, seu portador e o tratamento antirretroviral: implicações existenciais. São Carlos: EdUFSCar.

Torres, T. L., \& Camargo, B. V. (2008). Representações sociais da aids e da terapia anti-retroviral para pessoas vivendo com HIV. Psicologia: Teoria e Prática, 10(1), 64-78. 